\title{
Paracyphononyx scapulatus (Hymenoptera, Pompilidae), a koinobiont ectoparasitoid of Trochosa sp. (Araneae, Lycosidae)
}

\author{
Hebert da Silva Souza', Yuri Fanchini Messas', Fabiana Masago², \\ Eduardo Fernando dos Santos ${ }^{3}$, João Vasconcellos-Neto'
}

I Universidade Estadual de Campinas, Instituto de Biologia, Departamento de Biologia Animal, Rua Monteiro Lobato, 255, Campinas, São Paulo, Brazil 2 Universidade Estadual Paulista "Júlio de Mesquita Filho", Instituto de Biociências, Departamento de Farmacologia, Distrito de Rubiāo Júnior, s/n, Botucatu, São Paulo, Brazil 3 Universidade Estadual Paulista "Júlio de Mesquita Filho", Instituto de Biociências, Letras e Ciências Exatas, Departamento de Biologia Animal, Rua Cristóvão Colombo, 2265, São José do Rio Preto, São Paulo, Brazi

Corresponding author: Hebert da Silva Souza (hssouza.bio@gmail.com)

Academic editor: J. Neff | Received 5 August 2015 | Accepted 18 September 2015 | Published 30 November 2015

http://zoobank.org/83B4CF20-1B29-4D7C-9203-F925181A419E

Citation: Souza HS, Messas YF, Masago F, dos Santos ED, Vasconcellos-Neto J (2015) Paracyphononyx scapulatus (Hymenoptera: Pompilidae), a koinobiont ectoparasitoid of Trochosa sp. (Araneae: Lycosidae). Journal of Hymenoptera Research 46: 165-172. doi: 10.3897/JHR.46.5833

\begin{abstract}
The genus Paracyphononyx Gribodo, 1884 (Pompilidae) contains species that act as koinobiont parasitoids of cursorial spiders. Here, we record a new parasitism interaction involving the pompilid wasp Paracyphononyx scapulatus (Bréthes) and the hunter spider Trochosa sp. (Lycosidae), and we describe how the wasp develops on the spider. This study contributes new information about the interaction between koinobiont ectoparasitoid wasps and spiders, which probably arose independently in different groups of wasps.
\end{abstract}

\section{Keywords}

Atlantic forest, Lycosidae, Hunter spider, Larval development, Parasitoid wasp

Copyright Hebert da Silva Souza et al. This is an open access article distributed under the terms of the Creative Commons Attribution License (CC BY 4.0), which permits unrestricted use, distribution, and reproduction in any medium, provided the original author and source are credited. 


\section{Introduction}

The Pompilidae family contains about 5000 known wasp species worldwide. In the Neotropical region (Central and South America), around 1000 species have been described, belonging to 60 genera and five subfamilies (Pitts et al. 2006). In North America, 282 species have been documented in detail, belonging to 40 genera (Goulet and Huber 1993). In South America, this family has been studied in Brazil, Argentina, Uruguay, Paraguay, and Chile (Banks 1946, 1947, Bradley 1944) and, recent studies are being conducted in Colombia (Fernández 1995, 2000). Fernández (2000) reported 50 genera belonging to four subfamilies in South America; however, most of these genera require detailed taxonomic revision.

All species of Pompilidae use spiders as a food source for larval development, leading to their common name of "Spider Wasps" (Brothers and Finnamore 1993, Brothers 1995). Many species of this wasp family are idiobiont ectoparasitoids of cursorial spiders, building their nests in pre-existing holes in the soil or burrows dug by the wasps (Martins 1991). However, some koinobiont ectoparasitoids, belonging to the genus Paracyphononyx Gribodo, 1884 (Pompilidae), allow the host to resume activities after paralyzing it and laying a single egg on the spider's abdomen (Grout and Brothers 1982, Conley 1985, El-Hennawy 1996).

Paracyphononyx has been recorded in the tropics and warmer temperate regions throughout the world (Evans 1966), with nine species recorded in Brazil (Fernández 2000). Only three species of Paracyphononyx are known to use spiders as hosts, notably those belonging to the Lycosidae. These interactions were recorded in the Afrotropical region for $P$. africanus (Radoskowski, 1881), P. funereus (Lepeletier, 1845) in the Nearctic, and P. ruficrus (Klug, 1834) in the Palearctic.

The Lycosidae is distributed worldwide, containing small species (4-10 mm body length) that roam freely among stones or low vegetation, and larger species $(10-20 \mathrm{~mm}$ body length) that typically dig burrows (Foelix 2011). Besides the records of Lycosidae used by Pompilidae as hosts, recent studies have presented data of a lycosid parasitized by an acrocerid fly (koinobiont endoparasitoid; Toft et al. 2012) and egg sacs parasitized by wasps of the families Ichneumonidae and Platygastridae (Cobb and Cobb 2004, Bowden and Buddle 2012). The lycosid genus Trochosa comprises small to medium sized spiders (5.8-13.0 $\mathrm{mm}$ body length) which are often found at the edge of woods and in woodland habitats (Dreyer and Brady 2008). They usually are nocturnal in the adult stage (Workman 1978).

Here, we record the occurrence of a new parasitic interaction involving Paracyphononyx scapulatus (Bréthes) and the hunter spider Trochosa sp. (Lycosidae), with a description of wasp development.

\section{Methods}

At 11:30 on July 3, 2014, we found a lycosid spider (Trochosa sp.) with a Paracyphononyx scapulatus egg on its abdomen (Fig. 1A) in a fragment of Atlantic Forest in the 
municipally of Iracema do Oeste, Paraná, Brazil (24²9'11"S, 53²1'14"W). We collected the spider alive, and placed it in a plastic container $(12 \times 12 \times 10 \mathrm{~cm})$. We fed the spider with Musca domestica Linnaeus, 1758 (Muscidae) and kept the individual at natural conditions of temperature $\left(21^{\circ} \mathrm{C}\right)$ and photoperiod $(13 \mathrm{~h}$ of light and $11 \mathrm{~h}$ of darkness). We then observed the behavior of the spider as the parasitoid developed from a larva to an adult wasp. In parallel, we photographed the spider daily, to obtain a time-series of the development of the parasitoid. We recorded the period of each developmental stage, cocoon construction, and adult wasp emergence. We measured the length and width of the larva throughout its development by analyzing the photographs using the software ImageJ (National Institute of Health).

\section{Results and discussion}

The Paracyphononyx scapulatus egg ( $1.4 \mathrm{~mm}$ length and $0.8 \mathrm{~mm}$ width) was deposited on the anterior-dorsal region of the abdomen of a juvenile Trochosa sp. (abdomen: 9 $\mathrm{mm}$ length and $6 \mathrm{~mm}$ width; cephalotorax: $7 \mathrm{~mm}$ length and $5.8 \mathrm{~mm}$ width; Fig. 1A), and hatched after seven days. The host remained active (resting during the day and walking at night), while the attached larva gradually fed on the spider's hemolymph in the abdomen. This result indicates that $P$. scapulatus is a koinobiont parasitoid, like other species of Paracyphononyx for which the biology is known (Grout and Brothers 1982, Conley 1985, El-Hennawy 1996). Conley (1985) documented $P$. funereus (Lepeletier 1845) as a koinobiont parasitoid of the spider Geolycosa rafaelana (Chamberlin, 1928), causing high mortality to adult females during the winter. Grout and Brothers (1982) observed P. africanus paralyzing its lycosine host temporarily, depositing a single egg transversely on the concave anterodorsal surface of the spider abdomen, and then abandoning the host, which subsequently recovered normal activity. ElHennawy (1996) recorded the wasp P. ruficrus manipulating the behavior of a lycosid spider, inducing the host to construct a silken cocoon around itself.

The larval development of Paracyphononyx scapulatus includes five instars, evidenced by marked increase in size of the larva between each stage (Fig. 1B-F), doubling its length between the fourth and fifth instars (Fig. 2). The fifth instar larva killed the spider in the morning, 20 days after the egg hatched. The spider body was then completely consumed over the next two days. On the second day, the larva spun in different locations on the ground of the plastic container looking for suitable substrate to construct a cocoon (Fig. 1G). The larva located a suitable site on the afternoon of the second day (16:00), and required about 16 hours to construct the cocoon (cocoon: $16 \mathrm{~mm}$ length and $6 \mathrm{~mm}$ width). We observed the presence of meconium after six days in the portion of the cocoon that was fixed onto the substrate (Fig. 1H, arrow). An adult female wasp (15 mm length) emerged 32 days after cocoon construction, cutting its apical region (Fig. 1I-J). Fifty-four days was required for the development period from the egg hatching to adult emergence. This period is higher than that observed by El-Hennawy (1996) for the congeneric wasp $P$. ruficrus, which had a 30-day total development period. 


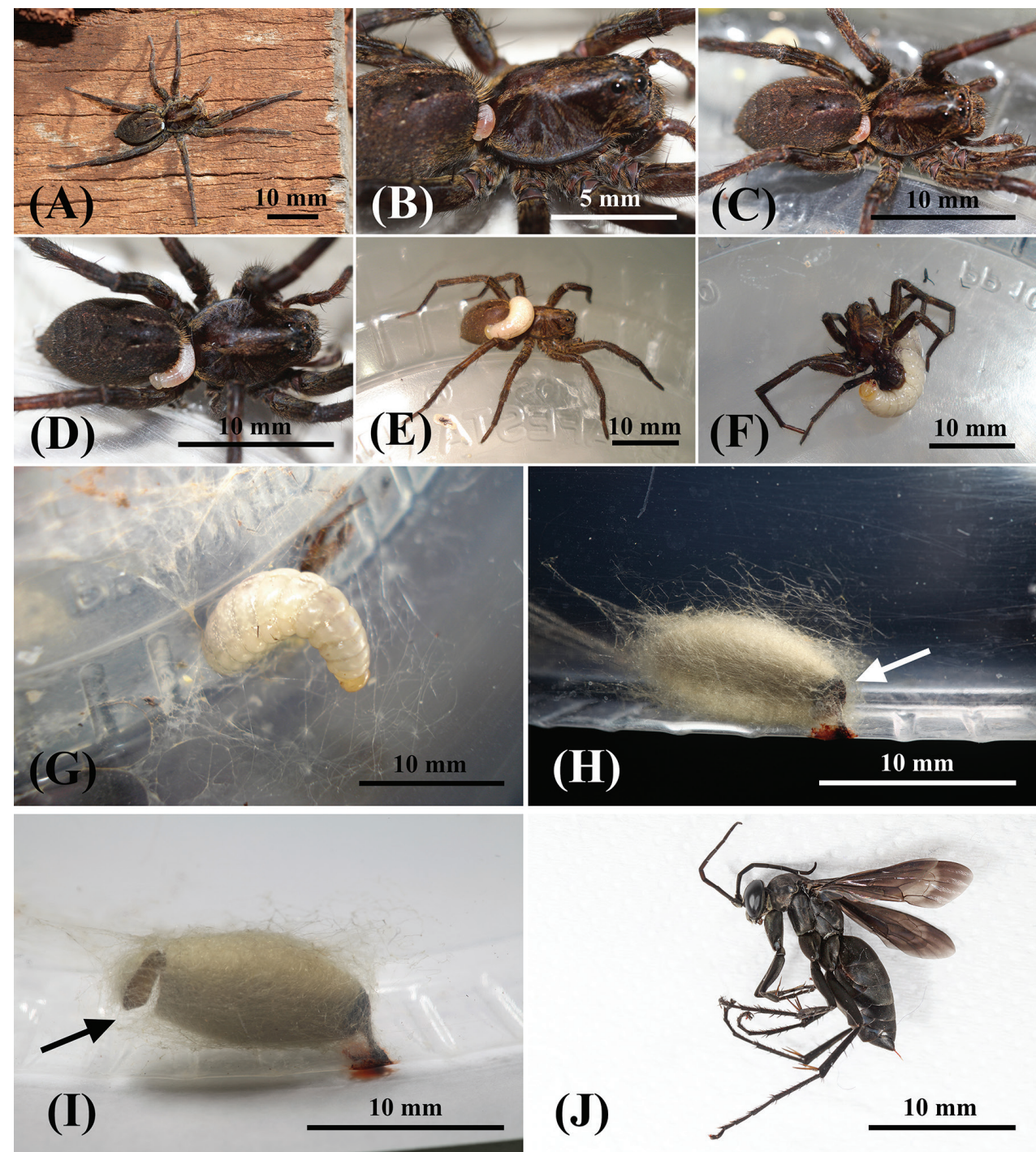

Figure I. Juvenile Trochosa sp. spider parasitized by the wasp Paracyphononyx scapulatus and containing on its abdomen: $\mathbf{A}$ the egg of the wasp; the $\mathbf{B}$ first $\mathbf{C}$ second $\mathbf{D}$ third, and $\mathbf{E}$ fourth instar larva of the wasp $\mathbf{F}$ the fifth instar larva of the wasp starting the consume the spider abdomen $\mathbf{G}$ the fifth instar larva constructing the cocoon $\mathbf{H}$ the cocoon containing the meconium (arrow) I the cocoon after adult wasp emergence (arrow indicates the location where the wasp emerged) $\mathbf{J}$ the adult female wasp. Photography: Hebert da Silva Souza (A-D), Eduardo Messas Junior (E-G), and Yuri Fanchini Messas (H-J).

To date, all observations involving Paracyphononyx as the koinobiont ectoparasitoid (Grout and Brothers 1982, Conley 1985, El-Hennawy 1996), including the present study, have shown that this wasp genus only uses spiders belonging to the Lycosidae as hosts. This observation indicates the existence of host-parasitoid specificity. 


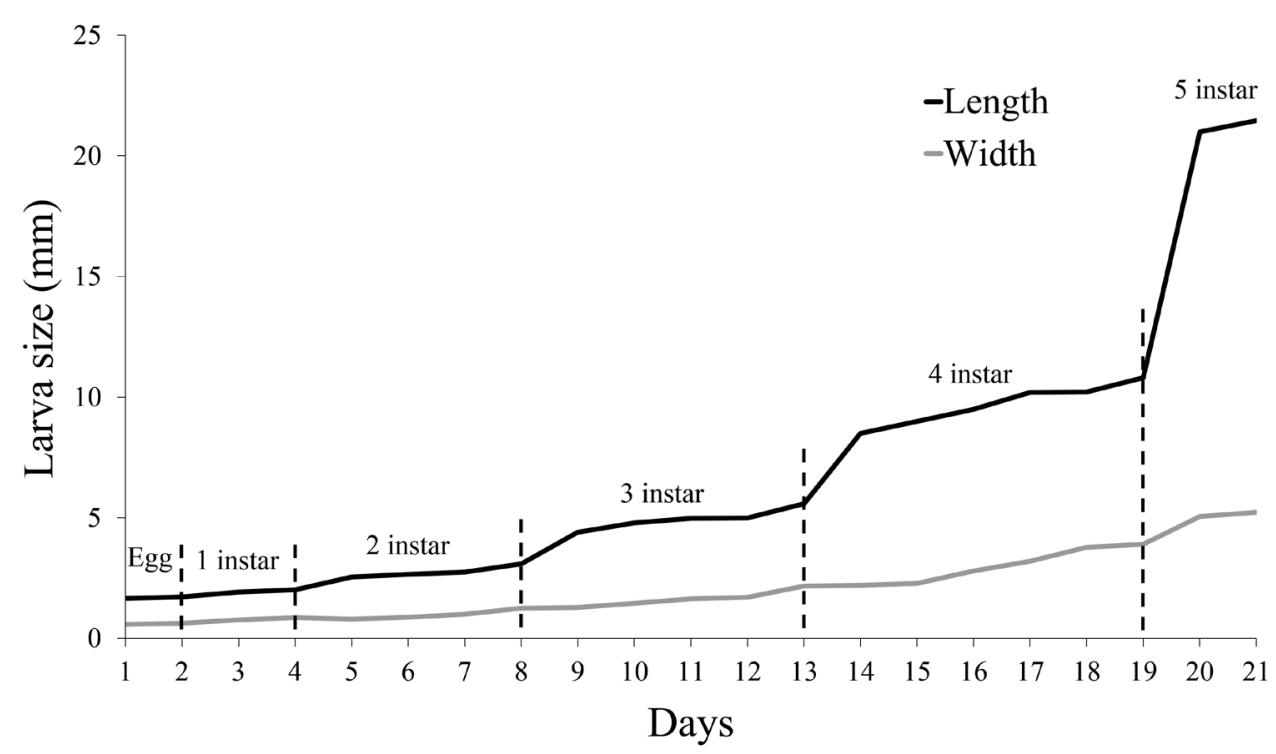

Figure 2. Size of Paracyphononyx scapulatus larva on the abdomen of the Trochosa sp. (length and width) during their development.

Koinobiont ectoparasitoids of the genus group Polysphincta (Hymenoptera: Ichneumonidae, Pimplinae) exhibit high parasitoid-host specificity, using only one species or groups of spider species that share common characteristics as hosts (Matsumoto and Konishi 2007, Sobczak et al. 2009, Gonzaga and Sobczak 2011, Takasuka and Matsumoto 2011, Eberhard 2013, Sobczak et al. 2014). Furthermore, parasitic wasps tend to select intermediate-sized hosts that have sufficient biomass for larval development, but do not represent a threat to the wasp during the attack (Gonzaga and Sobczak 2011). Few records exist of parasitism by Paracyphononyx; consequently, knowledge about the ecology and natural history of this genus remain limited. Therefore, we encourage future studies to elucidate the type of host selection used by this group of wasps.

Paracyphononyx scapulatus attacked the Trochosa sp. during winter, which is also when Conley (1985) recorded 50-60\% mortality of adult Geolycosa rafaelana females caused by $P$. funereus. The same author observed that the parasitism rates were not strongly related to reduced-density populations of $G$. rafaelana, indicating that $P$. funereus selectively forages in areas with higher spider density (Conley 1985). Thus, there may be a phenological adjustment between $P$. scapulatus and Trochosa sp., the period of wasp attacks coincides with the period when the number of juvenile spiders is at its peak, which provide sufficient biomass for adequate larval development.

We did not observe any behavioral modification by the larva on the parasitized Trochosa sp. After killing the spider, the Paracyphononyx scapulatus larva started cocoon construction much faster than that observed for P. ruficrus by El-Hennawy (1996). However, in the previous study the Lycosa host spun a silken chamber, clos- 
ing itself and the $P$. ruficrus wasp larva inside. Then, the wasp larva continued to feed on the spider inside the silken shelter, killing the host and building its cocoon. Similar behavior was observed by Day (1981) for Pompilus cinereus (Fabricius). Most known behavioral manipulation interactions induced by parasitoid wasps target web building spiders, with behavior modification tending to include the construction of modified webs which may exhibit a tridimensional tangle structure, absence of sticky spirals, central hub and stabilimentum, reduced number of radial lines and refuges that protect the cocoon and increase parasitoid survival (Eberhard 2013, Korenko et al. 2015). Data about the behavioral manipulation of pompilid hosts remains limited. In this study, having the spider caged in a featureless container did not allow us to test if the parasite tried to manipulate the spider behavior (e.g. induce it to hide itself and consequently hide the wasp cocoon). Thus, new records and more conclusive studies are necessary to understand the behavioral modification induced by Pompilidae species.

Many Pompilidae species hunt wandering spiders on the ground; consequently, immobilized spiders are exposed to predators, such as ants. Thus, these wasp species may dig burrows or use pre-existing holes to hide the paralyzed spider with its egg. In comparison, the type of koinobiont parasitism adopted by Paracyphononyx scapulatus (i.e., allowing the spider to continue normal activity), may be an alternative strategy to prevent the exposure hosts to predation. According to Korenko et al. (2011), most interactions between koinobiont parasitic wasps and spiders are host-specific, with the life histories of both wasp and spider being tightly coupled. Therefore, we would expect $P$. scapulatus to kill the host during the day at the end of the larval development under natural conditions, which is when the spider is typically resting in a refuge.

The genus-group Polysphincta is well-known to contain exclusively koinobiont ectoparasitoids of spiders (Gauld and Dubois 2006). Yet, knowledge about the hostparasite interactions of Pompilidae family have been summarized in a few studies that provide limited and brief information. Further investigations detailing these interactions may provide a promising path towards understanding the evolution of koinobiont ectoparasitism, which probably arose independently in different groups of wasps.

\section{Aknowledgements}

We would like to thanks Eduardo Messas Junior for the photographs and Antonio Domingos Brescovit for spider identification. We were financially supported by Instituto Nacional de Ciência e Tecnologia dos Hymenoptera Parasitoides da Regiáo Sudeste Brasileira (HYMPAR/Sudeste - CNPq/FAPESP/CAPES), Conselho Nacional de Desenvolvimento Científico e Tecnológico (CNPq - research grant to Santos, E. F.) and Coordenação de Aperfeiçoamento de Pessoal de Nível Superior (Capes - research grants to Messas, Y. F. and Souza, H. S.). 


\section{References}

Banks N (1946) Studies of South American Psammocharidae Part I. Bulletin of the Museum of Comparative Zoology 96: 311-525.

Banks N (1947) Studies of South American Psammocharidae Part II. Bulletin of the Museum of Comparative Zoology 99: 371-486.

Bowden JJ, Buddle CM (2012) Egg sac parasitism of Arctic wolf spiders (Araneae: Lycosidae) from northwestern North America. Journal of Arachnology 40: 348-350. doi: 10.1636/P11-50.1

Bradley JC (1944) A preliminary revision of the Pompilinae (Exclusive of the tribe Pompilini) of the America (Hymenoptera: Pompilidae). Transactions of the American Entomological Society 70: 23-157.

Brothers DJ (1995) The vespoid families (except vespids and ants). In: Hanson PE, Gauld ID (Eds) The Hymenoptera of Costa Rica. Oxford University Press, Oxford, 504-560.

Brothers DJ, Finnamore AT (1993) Superfamily Vespoidea. In: Goulet H, Huber JT (Eds) Hymenoptera of the World: an identification guide to families. Research Branch Agriculture Canada Publication (Otawa): 161-27.

Cobb LM, Cobb VA (2004) Occurrence of parasitoid wasps, Baeus sp. and Gelis sp., in the egg sacs of the wolf spiders Pardosa moesta and Pardosa sternalis (Araneae, Lycosidae) in southeastern Idaho. The Canadian Field-Naturalist 118: 122-123.

Conley RC (1985) Predation versus resource limitation in survival of adult burrowing wolf spiders (Araneae: Lycosidae). Oecologia 67: 71-75. doi: 10.1007/BF00378453

Day MC (1981) A revision of Pompilus Fabricius (Hymenoptera: Pompilidae), with further nomenclatural and biological considerations. Bulletin of the British Museum (Natural History), Entomology 42: 1-42.

Dreyer MD, Brady AR (2008) Trochosa sepulchralis, a senior synonym of Trochosa acompa, and the restoration of Trochosa abdita (Araneae, Lycosidae). Journal of Arachnology 36: 65-75. doi: 10.1636/H07-19.1

Eberhard WG (2013) The polysphinctine wasps Acrotaphus tibialis, Eruga ca. gutfreund, and Hymenoepimecis tedfordi (Hymenoptera, Ichneumonidae, Pimplinae) induce their host spiders to build modified webs. Annals of the Entomological Society of America 106: 652-660. doi: 10.1603/AN12147

El-Hennawy HK (1996) A spider (Lycosa? sp.) (Araneida: Lycosidae) providing a shelter for its predator Paracyphononyx ruficrus (Klug, 1834) (Hymenoptera: Pompilidae). Revue Suisse de Zoologie 1: 185-188.

Evans HE (1966) A revision of the Mexican and Central American spider wasps of the subfamily Pompilinae (Hymenoptera: Pompilidae). Memoirs of the American Entomological Society 20: 1-442.

Fernández F (1995) La biodiversidad de los Hymenoptera en Colombia. In: Rangel JO (Ed.) La Diversidad Biológica en Colombia. Universidad Nacional de Colombia, Bogotá, 373-442. Fernández F (2000) Avispas Cazadoras de Arañas (Hymenoptera: Pompilidae) de la Región Neotropical. Biota Colombiana 1: 3-24.

Foelix RF (2011) Biology of Spiders. Oxford University Press, Oxford, 419 pp. 
Gauld ID, Dubois J (2006) Phylogeny of the Polysphincta group of genera (Hymenoptera: Ichneumonidae; Pimplinae): a taxonomic revision of spider ectoparasitoids. Systematic Entomology 31: 529-564. doi: 10.1111/j.1365-3113.2006.00334.x

Gonzaga MO, Sobczak JF (2011) Behavioral manipulation of the orb-weaver spider Argiope argentata (Araneae, Araneidae) by Acrotaphus chedelae (Hymenoptera, Ichneumonidae). Entomological Science 14: 220-223. doi: 10.1111/j.1479-8298.2010.00436.x

Goulet H, Huber JT (1993) Hymenoptera of the World: an identification guide to families. Research Branch Agriculture Canada Publication, Ottawa, 668 pp.

Grout TG, Brothers DJ (1982) Behaviour of a parasitic pompilid wasp (Hymenoptera). Journal of the Entomological Society of South Africa 45: 217-220.

Korenko S, Michalková V, Zwakhals K, Pekár S (2011) Host Specificity and Temporal and Seasonal Shifts in Host Preference of a Web-Spider Parasitoid Zatypota percontatoria. Journal of Insect Science 11: 1-12. doi: 10.1673/031.011.10101

Korenko S, Satrapová J, Zwakhals K (2015) Manipulation of araneid spider web architecture by the polysphinctine parasitoid Zatypota picticollis (Hymenoptera: Ichneumonidae: Pimplinae). Entomological Science 18: 383-388. doi: 10.1111/ens.12132

Martins RP (1991) Biologia e comportamento de comunidades de vespas escavadoras (Hymenoptera: Aculeata). PhD thesis. Universidade Estadual de Campinas, São Paulo.

Matsumoto R, Konishi K (2007) Life histories of two ichneumonid parasitoids of Cyclosa octotuberculata (Araneae): Reclinervellus tuberculatus (Uchida) and its new sympatric congener (Hymenoptera: Ichneumonidae: Pimplinae). Entomological Science 10: 267-278. doi: 10.1111/j.1479-8298.2007.00223.x

Pitts JP, Wasbauer MS, Dohlen CD (2006) Preliminary morphological analysis of relationships between the spider wasp subfamilies (Hymenoptera: Pompilidae): revisiting an old problem. Zoologica Scripta 35: 63-84. doi: 10.1111/j.1463-6409.2005.00217.x

Sobczak JF, Loffredo APS, Penteado-Dias AM, Gonzaga MO (2009) Two new species of Hymenoepimecis (Hymenoptera: Ichneumonidae: Pimplinae) with notes on their spider hosts and behaviour manipulation. Journal of Natural History 43: 2691-2699. doi: 10.1080/00222930903244010

Sobczak JF, Moura-Sobczak JCMS, Messas YF, Souza HS, Vasconcellos-Neto J (2014) A new record of a host-parasitoid interaction: Hymenoepimecis veranii Lofredo \& Penteado-Dias, 2009 (Hymenoptera: Ichneumonidae) parasitizing Araneus orgaos Levi, 1991 (Araneae: Araneidae). Journal of Insect Behavior 27: 753-758. doi: 10.1007/s10905-014-9467-z

Takasuka K, Matsumoto R (2011) Lying on the dorsum: unique host-attacking behaviour of Zatypota albicoxa (Hymenoptera, Ichneumonidae). Journal of Ethology 29: 203-207. doi: 10.1007/s10164-010-0263-8

Toft S, Nielsen BO, Funch P (2012) Parasitoid suppression and life-history modifications in a wolf spider following infection by larvae of an acrocerid fly. Journal of Arachnology 40: 13-17. doi: 10.1636/P11-28.1

Workman C (1978) Life cycle and population dynamics of Trochosa terricola Thorell (Araneae: Lycosidae) in a Norfolk grass heath. Ecological Entomology 3: 329-340. doi: 10.1111/ j.1365-2311.1978.tb00934.x 